\title{
UMA ANÁLISE CRÍTICA SOBRE "THE ORIGIN OF SUFFIXES IN ROMANCE", DE DAVID PHARIES
}

\author{
A CRITICAL ANALYSIS ON "THE ORIGIN OF SUFFIXES \\ IN ROMANCE", BY DAVID PHARIES
}

Clóvis Luiz Alonso Fúnior*

Universidade de São Paulo, São Paulo, SP, Brasil

Resumo: № artigo "The Origin of Suffixes in Romance", constante no volume terceiro de Word-Formation: an International Handbook of the Languages of Europe, David Pharies constrói acurada tipologia das origens dos sufixos românicos. No artigo ora presente, tomo partido de certas posiçōes de Pharies para propor, em viés crítico, determinadas releituras minhas acerca de questões sobre que al se versa. A linha que persigo, como eixo verdadeiramente central, é a proposição do rendimento do binômio metáfora/metonímia como possivel motriz da constituição de fenômenos linguísticos, sobretudo de ordem morfológico-lexical..

Palavras-chave: sufixos; România; morfologia; metófora; metonímia.

Abstract: In his article "The Origin of Suffixes in Romance", which integrates the third volume of Word-Formation: an International Handbook of the Languages of Europe, David Pharies builds an accurate typology of the origins of the suffixes in Romance. In this paper, I defend some of the selected positions taken by the Author as to propose, by means of a critical bias, a possible interpretation regarding some of the topics approached by Pharies. My line of thought stands by the truly central axis, according which the binomy metaphor/metonymy might be the motor for the constitution of linguistic phenomena, mainly the morphological-exical kind..

Keywords: suffixes; romance; morphology; metaphor; metonymy.

* Universidade de São Paulo - USP, São Paulo, SP, Brasil; Programa de Filologia e Língua Portuguesa; alonso.junior@usp.br 
Linha D'Água (Online), São Paulo, v. 31, n. 2, p. 53-64, maio-ago. 2018

\section{Ilntrodução como que revisionista}

Trabalho de viés claramente tipologista, o artigo de David Pharies "The Origin of Suffixes in Romance", publicado no volume terceiro de Word-Formation: an International Handbook of the Languages of Europe, pode ser entendido como cuidadosa revisão bibliográfica não somente de trabalhos de preocupação romanista. Embora não explicitada, a assunção teórica fundamental do texto é a divisão das formações dos tipos de sufixos entre formações de motivação "formal", que propriamente se pode traduzir por segmental, formações de motivação semântica e formações de motivação gramatical - “(...) development of new suffixes, mostly through reanalysis and semantic or grammatical change (...)” (PHARIES: 2015, p. 1854) -, distinção alguma vez relativizada por Pharies (2015, p. 1856):

Rainer's [2002] ${ }^{1}$ analysis is unusual in classifying reanalysis as a form of semantic change. It may be true that associating chasseur with chasse rather than chasser involves a change in the semantic interpretation of the word, but ${ }_{[?]}$ if so, it is an exceedingly subtle change. Conversely, it is interesting that Rainer views contamination and blending of suffixes to be a category separate from semantic change. As I show below, contamination and merger of suffixes are often accompanied by semantic changes.

Sobre a reanálise, reanalysis, fenômeno propriamente segmental, são apreciáveis não só a acuidade de Pharies na percepção de que se envolve certa mudança de interpretação semântica da palavra, mas, sobretudo, a ressalva de que se está em nível de sutileza, o que aponta para a postura inortodoxa de Rainer (2002), porquanto - consideração que fortaleceria a ressalva de Pharies — a reanálise indicia precipuamente mudança de interpretação do falante ${ }^{2}$ relativamente à produtividade linguística, bem mais do que matização semântica da palavra.

1 RAINER, F. Convergencia y divergencia en la formación de palabras en las lenguas románicas. In: GARCÍA-MEDALL, J. (Ed.) Aspectos de morfología derivativa del español. Lugo: Tris Tram, 2002, p. 103-33.

2 assim como é função da interpretação do falante a mudança formal do neutro plural latino para o feminino singular românico, dada a identidade também formal entre ambos:

"In the evolution of Fr. -aie 'planted area', there is a reinterpretation of a Latin suffix in terms of gender and number, as its Latin etymon -êta is a neuter plural that is reinterpreted in French as a

ALONSO JÚNIOR, C.L. Uma análise crítica sobre "The Origin of Suffixes in Romance", 
Linha D'Água (Online), São Paulo, v. 31, n. 2, p. 53-64, maio-ago. 2018

Pharies se debruça sobre a elaboração de cuidadosa tipologia das origens dos sufixos românicos, que muito aproveita a quem, de algum modo, se devota ao problema, nomeadamente estudiosos e Professores de línguas romanças e de Filologia Românica, área tradicionalmente preocupada com aspectos morfológicos. Aqui esboço uma análise crítica não $d a$ tipologia ali estabelecida, mas sobre algumas considerações ali presentes; mais do que isso, aproprio-me daquelas considerações para, com base nelas e não sem algum oportunismo, tecer esboço das minhas, o que espero que também aproveite àqueles interessados.

\section{Graus de afeto}

Antes de tipologizar as origens dos sufixos românicos, Pharies menciona trabalhos pioneiros sobre tipologia de sufixos e especifica determinada mudança semântica ocorrida no sufixo alemão -ling: “(...) semantic change (Germ. Dichter-ling lit. 'small poet' > 'unskilled poet')" (PHARIES: 2015, p. 1855). O caráter tipologizante do artigo o desobriga de elucubrações semânticas, que, se entendidas como prática especulativa, há muito não são frequentes nos discursos sobre linguagem, sob pena da acusação de anticientificidade. Na passagem, porém, do sentido "pequeno" (Dichter-ling "pequeno poeta") para o sentido "inexperiente" (Dichter-ling "poeta inexperiente") e mesmo para o sentido "inábil" (Dichter-ling "poeta inábil”), chamo atenção para a possibilidade de que se veja um tipo particular de mudança semântica: a mudança - aceita como tal porque de fato o é - caracterizada, entretanto, como extensão semântica, especificação semântica oriunda daquela extensão, por via do processo metonímico que faz entender a consideração de inexperiência e também a de inabilidade — já vistas como con-sequência uma da outra — como desdobramento possível da consideração de pequenez, como ponto de chegada do processo extensivo de apequenamento. É no mesmo processo metonímico que, em Português, poetinha pode significar "pequeno poeta", criança que se põe a versejar, e, como tal, pode indiciar a ideia de "poeta iniciante", inexperiente na técnica, sentidos que clamam a veiculação de certa indulgência afetiva, em que a pequenez se

feminine singular, of. olivaie, oliveraie 'olive grove' ( $\leftarrow$ olive), oseraie 'osier or willow plantation' $(\leftarrow$ osier 'osier, willow')." (PHARIES: 2015, p. 1857) [item consagrado à mudança gramatical] 
Linha D'Água (Online), São Paulo, v. 31, n. 2, p. 53-64, maio-ago. 2018

associa extensivamente a terna fragilidade, configurando-se o diminutivo afetivo, bem como pode indiciar, na mesma esteira metonímica, a ideia de "mau poeta", propriamente imperito, quer por insciência daquela técnica e da tradição a ela associada, quer por inabilidade inata, em associação extensiva da pequenez a indesejável insignificância, desembocando-se em determinado diminutivo depreciati$\mathbf{v o}^{3}$, coerentemente sinônimo do aumentativo poetastro, formação também depreciativa ${ }^{4}$ que emblema recurso por meio do qual se parece fazer redundar a ideia de

3 Análogo é o processo metonímico verificado na extensão - "aproximação", approximation, para Rainer (2002), segundo Pharies $(2015$, p. 1856) - para sentido figurado, de cunho fortemente avaliativo, do uso do sufixo castelhano -zno, fenômeno que aqui proponho como diverso do processo stricto sensu metafórico verificado na gramaticalização do advérbio latino mente:

"The other two types of semantic change [cited by Rainer (2002)] are 'approximation', through which the suffix of lobezno 'wolf cub', applied originally only to wild animals (as here, to lobo 'wolf'), is extended to certain undesirable humans, e.g., rufezno 'young ruffian' $\leftarrow$ rufián 'rogue $\left.\right|_{\left[{ }^{\prime}\right]}$ and grammaticalization, exemplified by -mente.".

4 Tomar à má parte a categoria "animais selvagens", wild animals, é o que promove a extensão do uso do sufixo para "humanos indesejáveis", undesirable humans, em relação de contiguidade, paralela à relação imageticamente parabólica, scilicet metafórica, que proponho para a interpretação da passagem de tranquillā mente para tranquilamente, que, se significa "de modo tranquilo", não deixa de significar "de espírito tranquilo", considerado o espírito do modo, o viés da maneira, o caráter da circunstância, em contrariedade à afirmação de Pharies $(2015$, p. 1861) segundo a qual "(...) Sp. afortunada-mente 'fortunately' (...) cannot refer to a state of mind", negando-se a relação entre o modo afortunado e o espírito afortunado desse modo:

"We explained above that the adverbializing suffix Sp., Port., Ital. -mente, Fr., Cat. -ment is the only clear case of suffix origin through grammaticalization in Romance (...). The process occurs when phrases such as tranquilla mente 'with a tranquil mind' (where mente is the ablative singular form of mens, mentis 'mind'), are interpreted as referring to manner generally (here, 'in a tranquil way'), thus opening the door for the formative to be attached to any adjective whatever, e.g., Sp. afortunada-mente 'fortunately', which cannot refer to a state of mind.",

passo que me parece caracterizado por sutil contradição interna, localizada no fato de que a generalidade de poder tratar-se de qualquer adjetivo para a formação do advérbio é que aponta, ela mesma, para a associação entre a maneira como determinada circunstância se dá e o espírito que há nessa maneira e, por conseguinte, nessa circunstância; se tranquillā mente "mudou para" tranquilamente - assumido o fenômeno imediato de mudança morfossintático-semântica -, permanece aí, na passagem, no terminus ad quem, no caráter circunstancial do adjunto adverbial, quer latino, quer românico, a ideia de "em/com 'mente' tranquila", verificada, então, a permanência ontológica da natureza morfossintática adverbial — preconizo a atribuição de realidade ontológica às entidades linguísticas - e do matiz semântico abstrativo: verificável, pois, a permanência na mudança.

"(...) In general, both diminutive and augmentative suffixes may be expected to develop pejorative overtones through metonymy, as they are applied to bases that are not expected to be small (profesor-cito 'inconsequential little teacher' $\leftarrow$ profesor 'teacher') or large (orej-ón 'ridiculously large ear' $\leftarrow$ oreja 'ear')." (PHARIES: 2015, p. 1858), consideração que pouco ou nada se 
Linha D'Água (Online), São Paulo, v. 31, n. 2, p. 53-64, maio-ago. 2018

grande tamanho na ideia de tamanho excessivo, desproporcional, sobejo, desqualificação de que resulta o aumentativo depreciativo, por processo metafórico ${ }^{5}$.

Note-se que problematizo a posição de Pharies — já apresentada em nota (veja-se a nota 4) - segundo a qual o aumentativo depreciativo seja motivado metonimicamente - “(...) In general, both diminutive and augmentative suffixes may be expected to develop pejorative overtones through metonymy (...)" (p. 1858) —: é de fato tênue a linha que divisa o grande conjunto figurativo composto por metonímia e metáfora, sendo talvez a primeira certa especificação da segunda, mas é preciso observar que o processo metafórico parece fazer empenhar certa proposição de similitude entre os objetos aproximados, não ex nibilo, mas a partir de alta subjetividade que estabelece, ela mesma, a analogia; o movimento

coaduna com a aparente aquiescência de Pharies à posição de Meyer-Lübke (1923) [MEYER -LÜBKE, W. Grammaire des langues romanes. Tome deuxième: Morphologie. Paris: Welter, 1923.], ora quanto ao diminutivo depreciativo:

"(...) Meyer-Lübke (1923, § 452) explains the semantic change as follows: 'Mais alors le sens de 'ressemblance' exprimé par l'adjectif s'est développé dans une direction toute différente; un objet analogue à un autre fut considéré comme inférieur à lui, comme plus petit, et voilà comment -inu, dans l'italien et le portugais notamment, est devenu un suffixe diminutif très employé.' (...)" (PHARIES: 2015, p. 1858).

A afirmação de notada diferença, "direction toute différente", há de ser relativizada, se não desconstruída, por meio da consideração da extensão metonímica: um profesorcito "professor inconsequente" não é expressão resultante de direção totalmente diferente da que fez chegar a "professor pequeno", ou seja, um professor inconsequente $\underline{\mathbf{e}}$, metonimicamente, um professor pequeno, atendida a prerrogativa de que, nos efeitos do processo metonímico e também do processo metafórico, embora haja inquestionável re-direcionamento - não "des-direcionamento" - discursivo-semântico, não há total esvaziamento da carga de significação "original", porque é exatamente sobre ela que se operam aqueles processos.

5 Veja-se a inconsistência de Caldas Aulete (DICIONÁRIO CALDAS AULETE Digital) na especificação de que o sufixo -astro indicie aumento de características já negativas:

"-astro 2 suf. 1. nom. = 'aumento (esp. de más qualidades)'; 'aquele que é muito ruim em algo, ou que tem péssimas qualidades': criticastro, filosofastro, medicastro, musicastro, poetastro, politicastro, pulhastro.

[F.: De or. incerta, posv. expressiva. É característico neste suf. o valor depreciativo.]".

Observe-se que não é acidental o fato de que, em toda a série de exemplos, o único adjetivo substantivado que no grau normal já se relaciona a característica tomada como negativa é pulhastro, aumentativo de pulha, em que a ideia de "grande pulha" é não redundantemente formalizada, por meio do sufixo; os outros adjetivos substantivados não necessariamente veiculam ideia negativa no grau normal, de que se deduz que o sufixo não indicia aumento "especialmente de más qualidades", mas tão somente indicia aumento, o que constrange a entender que se trate de outro fenômeno, aquele segundo o qual o próprio aumento é desqualificativo, por via metafórica.

ALONSO JÚNIOR, C.L. Uma análise crítica sobre "The Origin of Suffixes in Romance", 
Linha D'Água (Online), São Paulo, v. 31, n. 2, p. 53-64, maio-ago. 2018

propriamente metonímico prescinde, por sua vez, de percepção que ultrapasse o nível da contiguidade como que já dada pela adjacência. A pouca habilidade de um jovem poeta ainda não deu lugar ao passo linearmente seguinte, que é a habilidade que se avizinha e há de atualizar-se em momento subsequente; tal poeta é pequeno e é pequeno como poeta, e sua dupla pequenez está presente na juventude e na consequente pouca habilidade, fato que legitima a indulgência e faz constituir o diminutivo afetivo. A inabilidade do mau poeta é carência, resultante do malogro daquele passo seguinte; aí está a pequenez que equivale a insuficiência e faz constituir o diminutivo depreciativo. Parece que, assim, estão lado a lado a figura do pequeno poeta menino, a do pequeno poeta ainda graciosamente pouco hábil e a do pequeno poeta indesejavelmente inábil. Não parecem, por outro lado, inserir-se em sequência de contiguidades a figura de um poeta corporeamente grande e a de um poeta ruim; não é à ideia de "grandeza" que se associa a desqualificação, mas é à ideia de dimensão desajeitadamente grande, então indesejável, daí desqualificável, processo que não parece caber nos limites da metonímia, fazendo recorrer ao engajamento representado pela metáfora, para a constituição do aumentativo depreciativo. Note-se no passo de Pharies (2015, p. 1858) -

(...) In general, both diminutive and augmentative suffixes may be expected to develop pejorative overtones through metonymy, as they are applied to bases that are not expected to be small (profesor-cito 'inconsequential little teacher' $\leftarrow$ profesor 'teacher') or large (orej-ón 'ridiculously large ear' $\leftarrow$ oreja 'ear').

- a relativa falta de paralelismo entre o exemplo abstrativo do diminutivo, de cunho moral, "profesor-cito 'inconsequential little teacher", e o exemplo cabalmente físico-concreto do aumentativo, pouco provido de figuração, “orej-ón 'ridiculously large ear", ambos ali associados à motivação metonímica: orejón parece fazer pensar em "orelha grande", característica física que se pode considerar ridícula, mas não faz pensar em outro objeto ${ }^{6}$, ou seja, a denotação não se estende a outro

6 Metonímia se dá, em Português, na constituição do significado "aparelho tecnológico" - "Tipo de cabine de telefone público instalada nas ruas, que lembra uma grande orelha." (DICIONÁRIO CALDAS AULETE Digital) [realce meu] —, fenômeno em que um significado se estende a outro.

ALONSO JÚNIOR, C.L. Uma análise crítica sobre "The Origin of Suffixes in Romance", 
significado, fato que reclama melhor exemplo de aumentativo depreciativo; talvez esteja aí indício da maior exigência empenhada no acionamento da formação daquele aumentativo, que preconizo motivado pelo processo metafórico.

A proposição de que a linha diminutiva - "pequeno poeta" > "poeta iniciante" / "mau poeta" - represente processo metonímico contradiz, segundo o que proponho aqui, a aparente arbitrariedade que há na formação dos opostos discursivos representados pelo diminutivo afetivo e pelo diminutivo depreciativo, fenômeno que bem parece corroborado pelo aumentativo afetivo, que se dá por via de valorização da grandeza, em que a contiguidade da metonímia se faz - diferentemente do que proponho para a constituição do aumentativo depreciativo - mais presumível do que o acionamento da metáfora propriamente dita, por via da adjacência vislumbrável entre avantajada dimensão física e avantajada dimensão moral, na chave da ausência de toda carência e da presença de grandeza imaterial. Desfaz-se, uma vez mais, a presunção de arbitrária desconexão ora entre os aumentativos figurativos: para processos e formações morfológicos que aí se situem, é insuficiente falar de mudança semântica desassociadamente da figuração, seja em processo metonímico, seja em processo metafórico, porquanto a mudança semântica é fenômeno que, já por si, convida a cogitar na atuação figurativa.

\section{Metonímia produtiva}

O fenômeno metonímico exatamente no qual se insiste aqui é, se não bem tematizado, bastante bem expresso por Pharies (2015, p. 1857-8), por via do estabelecimento de cadeias semânticas:

(...) In several cases (...) it appears that, after an ellipsis has the effect of deriving nouns from adjectives, suffixes take on meanings associated with their bases. Thus, the Latin adjectival suffix - alis (as in nävälis 'nautical, naval' $\leftarrow$ nävis, -is 'ship') $)_{[s i c]}$ acquires in Spanish the meaning 'area populated by a certain kind of plants' through the following sequence of associations: junco 'rush' $\rightarrow$ juncal 'relative to rushes' $\rightarrow$ campo juncal 'rush bed' $\rightarrow$ juncal 'id.'. Also through ellipsis, the suffix of pertinence, color and material -ineus (as in lactineus 'milk-colored' $\leftarrow$ lac, lactis 'milk'), ${ }_{[\text {sic }}$ extends its reach to inhabitant names in cacereño '(person) from Cáceres' through the association 'pertinent to Cáceres' $\rightarrow$ 'inhabitant of Cáceres'. 
Linha D'Água (Online), São Paulo, v. 31, n. 2, p. 53-64, maio-ago. 2018

This change is also documented in Italian, cf. mornesigni 'inhabitant of Mornese' $(\leftarrow$ Mornese) (...),

em que "campo juncal 'rush bed' $\rightarrow$ juncal 'id." proponho que não necessariamente faça pressupor a ocorrência - ainda que posta simplesmente no nível da reconstituição - da palavra campo, devendo-se entender a possibilidade da presença de equivalentes semânticos, uma vez que a palavra poderia ser outra, como plantación/plantação - plantación juncal / plantação juncal -, do que se deduz que tenha sido a ideia da qualificação própria daquele adjetivo - juncal - o que configurou a atribuição extensiva dessa ideia a todo o conjunto — de "elementos juncais" - estabelecido em dado espaço do mundo: um conjunto de juncos é um conjunto "juncal", portanto um juncal, por via de mão dupla constituída pela metonímia e, sobretudo no nível estritamente linguístico-sintagmático, pela elipse, fenômeno que já bem se manifesta aí, tão presumivelmente quanto em aplicação ao comportamento do "suffix of pertinence, color and material -ineus", caracterização em que traços materiais como a cor e a própria matéria podem mesmo configurar a pertença; extensivamente se interligam, sem obra do acaso, os sentidos "matéria", "cor" e "pertença", dos quais os dois primeiros, em olhar desatento à operação metonímica, parecem, e apenas parecem, incongruentes com o último; ora, ambas já encampadas pelo frame "materialidade", a própria ideia de matéria e a ideia de cor - cor da matéria - configuram os seres que, genericamente, pertencem a determinado lugar, sendo, pois, ideias que, por entimema, caracterizam o próprio lugar, perfazem o pertencimento, deixando-se verificar a atuação da cadeia extensiva.

\section{Gramaticalização e outros fenômenos imagéticos}

Na composição do item Grammaticalization, Pharies (2015, p. 1862) atenta à derivação românica do grego $\lambda$ ó ${ }^{\circ}$ :

(...) certain constituents of Greco-Latin learned compounds can occur initially as well as finally, e.g., geólogo 'geologist' vis-à-vis logo-terapia 'speech therapy'. This (...) is neutralized by the fact that the newly grammaticalized suffix being

ALONSO JÚNIOR, C.L. Uma análise crítica sobre "The Origin of Suffixes in Romance", 
posited is not -logo but -ólogo, which is unlikely to be associated with the first element in logoterapia. (...).

A natureza do fenômeno em que se fazem enquadrar -logo e -ólogo não lhes confere, entretanto, a desvinculação que ali se pretende, tomada aqui a posição de que a gramaticalização não gere total esvaziamento semântico. $\mathrm{O}$ fato de o alomorfe -ólogo conter a vogal de ligação, que, como tal, se limita à tarefa não mais do que fonética de proceder à ligação entre a base e o original -logo, não indicia que -logo e -ólogo sejam duas entidades ontologicamente distintas. Negar a identidade ontológica e, portanto, semântica entre -ólogo, de geólogo, e -logo, de logoterapia, é negar a percepção de um passo situado aquém da extensão metonímica; é mesmo não considerar a singela extensão - que não apela para a metonímia - de -logo como propriamente $\lambda$ ó altamente polissêmico em grego (de uma polissemia, entretanto, coerentemente sequenciada, que vai de "palavra" a "discurso"), para -ólogo como "aquele que estuda, observa, teoriza", scilicet, "aquele que estuda, observa, teoriza a palavra" ou "por meio da palavra". Em -logo, tem-se a palavra propriamente como objeto, ainda que objeto instrumental, como "terapia pela palavra"; em -ólogo, embora haja nomeação direta do agente, tem-se a palavra como meio/instrumento em psicólogo, "aquele que observa a alma com grande fundamentação na palavra”, e como objeto central em filólogo, "aquele que centralmente se amiga com a palavra": sempre se tem a palavra, critério semântico que, mesmo que alijado por determinada concepção teórica, não permite a proposição daquela desvinculação.

Pharies (2015, p. 1857) considera mudança gramatical a amplificação das possibilidades de derivação:

The Latin adjective suffix - ānus, for example, which admits primarily noun stems (urbānus 'urban' $\leftarrow$ urbs, -bis 'city'), differs from its Romance reflexes in their expanded list of admissible input categories, cf. Ital. sottano 'inferior' from the adverb sotto 'under' and Sp. lejano 'distant', from the adverb lejos 'far'. (...),

apreciação a que se poderia objetar que mais se trata de fenômeno linguístico de formação de palavras do que daquilo que se costuma chamar mudança gramatical; instigante seria perscrutar aquele fenômeno, na esteira da concepção 
Linha D'Água (Online), São Paulo, v. 31, n. 2, p. 53-64, maio-ago. 2018

de que elementos formadores substantivos e elementos formadores advérbios são todos nomes, fato que muito os aproxima ontologicamente e faz ultrapassar a mera descrição estemática.

Subtipo que, para Rainer $(2005)^{7}$, segundo Pharies (2015, p. 1856), se relaciona a quadro categórico anterior (RAINER: 2002), a "aproximação" que se opera no nível da base é, muito ao contrário das categorias precedentes, proposição teórica de cunho extralinguístico:

(...) 'approximation' is divided into two subtypes, according to whether the semantic change is located at the level of pattern or base. The best example of the former is the prefix mega-, which according to Rainer was assigned the meaning 'one million $x$ ' at a scientific conference in 1960, a change that took place independently of any specific derivative in mega-. (...),

do que se entende que, na necessidade de escolher termo que nomeasse a grandeza "um milhão", deliberou-se que fosse mega, elemento disponível na Língua; não se trataria de decodificar o elemento linguístico, realizando-se, ora sim, o movimento que vai da necessidade pragmática do mundo para o arsenal sistêmico da Língua, não se procedendo aí a nenhum movimento de investigação intralinguística, decerto excetuada a observação da semântica original do termo: é essa observação, etimológica, e o aquilatamento da adequação da semântica à necessidade objetal do mundo o que faz epistemologicamente relevante a categoria ali proposta.

Mais do que didatismo, aprecie-se a preocupação metodológica de Pharies no passo em que se problematiza a classificação de Haspelmath $(1995)^{8}$, ao se apontar a fragilidade da demonstração da distinção entre affix telescoping, que talvez se possa traduzir por "afixo de encaixamento", e conglutination, "conglutinação", fenômenos cujas exemplificações, segundo Pharies, não bastam para esclarecer a distinção entre ambos. Trata-se de subcategorias do fenômeno da reanálise estabelecidas por Haspelmath, seguidas de um terceiro tipo, nomeado secretion, "secreção" “(...) Haspelmath's third category is called 'secretion', whereby a part of a root is

7 RAINER, F. Semantic change in word formation. Linguistics 43: 415-41, 2005.

8 HASPELMATH, M. The growth of affixes in morphological reanalysis. In: BOOIJ, G.; MARLE, J. van (Ed.). Yearbook of Morphology 1994. Dordrecht: Kluwer, 1995, p. 1-29.

ALONSO JÚNIOR, C.L. Uma análise crítica sobre "The Origin of Suffixes in Romance", 
Linha D'Água (Online), São Paulo, v. 31, n. 2, p. 53-64, maio-ago. 2018

reanalyzed as part of an affix, cf. Fr. fruit-ier 'fruit grocer' is reanalyzed as frui-tier, making possible bijou-tier 'jeweler' ( $\leftarrow$ bijou 'jewel').” (PHARIES: 2015, p. 1855) -, palavra cuja propriedade para aquilo a que se destina é bem imageada por meio da observação da raiz indo-europeia *sē, que indicia justamente a ideia de se-paração, o mesmo a valer quanto à raiz *krei, que indicia a mesma ideia; uma vez que, em Língua, redundância é tão só explicitação de coerência, formou-se, coerente-

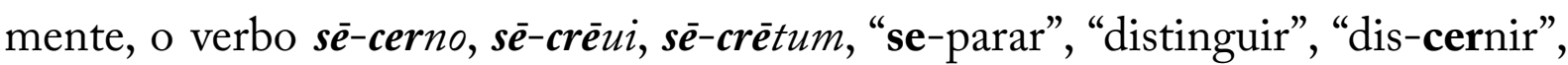
"justa posição" das raízes *sēe * krei, fixado propriamente como adjetivo o particípio perfeito sēcrētus, "secreto" porque "separado", depois substantivado em sēcrētum, "re-tiro", "segredo", "coisa secreta" porque "coisa separada", resultados lexicais de metáfora de inspiração físico-espacial, com desdobramento abstrativo9. Sem metáfora, o fenômeno da secreção, subcategoria da reanálise para Haspelmath (1995), é exatamente a se-creção, scilicet a se-paração, morfológica.

\section{Inconclusão}

Apesar da perceptível preocupação metodológica que perpassa todo o texto, é preciso apontar o modo abrupto como Pharies o encerra, escolha que causa estranheza e sensação de incompletude, uma vez destacado o texto do conjunto de publicações a que pertence. $O$ fato verdadeiramente não invalida o trabalho, sobretudo quanto ao aspecto sistematizador e quanto à presença das boas reflexões que se oferecem à comunidade acadêmica.

\footnotetext{
9 "(...) é na estrutura das 'formas da intuição' que primeiramente se manifestam o tipo e a orientação da síntese espiritual que opera na linguagem, e é somente por intermédio destas [sic] formas, somente através [sic] da veiculação das intuições de espaço, tempo e número que a linguagem pode realizar a sua função essencialmente lógica: a de transformar impressões em representações.

Este [sic] entrelaçamento da expressão sensível e [da expressão] espiritual na linguagem evidenciase sobretudo na intuição do espaço. O papel decisivo da intuição espacial ressalta com a máxima nitidez justamente nas expressões mais gerais que a linguagem cria para designar processos espirituais. Até mesmo nas línguas altamente desenvolvidas encontramos esta [sic] reprodução 'metafórica' de determinações espirituais através [sic] de representações espaciais." (CASSIRER: 2001, p. 208.) [realce meu]
}

ALONSO JÚNIOR, C.L. Uma análise crítica sobre "The Origin of Suffixes in Romance", 
Linha D'Água (Online), São Paulo, v. 31, n. 2, p. 53-64, maio-ago. 2018

\section{Referências}

AULETE, C. Dicionário Contemporâneo da Lingua Portuguêsa. Rio de Janeiro: Delta, 1958.

CASSIRER, E. A filosofia das formas simbólicas: a linguagem. São Paulo: Martins Fontes, 2001. (Coleção Tópicos.)

DICIONÁRIO CALDAS AULETE Digital. Disponível em: <http://www.aulete.com.br>. Acesso em: 18.12.2017.

GAFFIOT, F. Dictionnaire illustré latin-français. Paris: Hachette, 1970.

HOUAISS, A. Dicionário da Lingua Portuguesa. Rio de Janeiro: Nova Fronteira, 2001.

MEILLET, A.; VENDRYES, J. Traité de Grammaire Comparée des Langues Classiques. 4. ed. Paris: Librairie Ancienne Honoré Champion, 1966.

PHARIES, D. The Origin of Suffixes in Romance. In: MÜLLER, P. et al. (Ed.) Word-Formation: an International Handbook of Languages of Europe. Volume 3. Berlin: De Gruyter Mouton (Handbücher zur Sprach- und Kommunikationswissenchaft / Handbook of Linguistics and Communication Science), 2015, p. 1854-66.

SARAIVA, F. R. S. Novissimo diccionario latino-portuguez. 2. ed. Rio de Janeiro: Garnier, Paris: Mellier, Lisboa: Bertrand, s. $d$.

TORRINHA, F. Dicionário latino-português. 3. ed. Porto: Marânus, 1945.

Recebido: 10/6/2018.

Aprovado: 27/8/2018.

ALONSO JÚNIOR, C.L. Uma análise critica sobre "The Origin of Suffixes in Romance", 